\title{
Antitumor Effect of Ginsenosides: A Systematic Review
}

\author{
Jing $\mathrm{Wu}^{1 * \#, ~ S h u a i s h u a i ~} \mathrm{Niu}^{2 *}$, Guan $\mathrm{Li}^{2 *}$, Qing Tian ${ }^{3 *}$, Ying Xiang2,3\# \\ ${ }^{1}$ Department of Morphology, School of Basic Medicine, Health Science Center, Yangtze University, Jingzhou, China \\ ${ }^{2}$ Laboratory of Oncology, Center for Molecular Medicine, School of Basic Medicine, Health Science Center, Yangtze University, \\ Jingzhou, China \\ ${ }^{3}$ Department of Cell Biology and Genetics, School of Basic Medicine, Health Science Center, Yangtze University, Jingzhou, China \\ Email: "653186525@qq.com, "xying316@163.com
}

How to cite this paper: $\mathrm{Wu}, \mathrm{J}$., Niu, S.S., Li, G., Tian, Q. and Xiang, Y. (2021) Antitumor Effect of Ginsenosides: A Systematic Review. Yangtze Medicine, 5, 207-225. https://doi.org/10.4236/ym.2021.53020

Received: March 10, 2021

Accepted: September 14, 2021

Published: September 17, 2021

Copyright (c) 2021 by author(s) and Scientific Research Publishing Inc. This work is licensed under the Creative Commons Attribution International License (CC BY 4.0).

http://creativecommons.org/licenses/by/4.0/ (c) (i) Open Access

\begin{abstract}
Tumor is a serious disease that threatens human health and has a high mortality. Chemotherapy is the most commonly used treatment, but it has a lot of side effects due to its toxicity. It has been found that ginsenosides exert an effective antitumor role. Ginsenosides are a class of triterpenoid saponins primarily found in the plant genus Panax. Many monomer components are studied, the most often investigated are Rg3, and Rh2, etc. Reports have shown that ginsenosides can inhibit tumor cells by suppressing proliferation and metastasis, and promoting apoptosis. In addition, ginsenosides can enhance sensitivity to conventional chemotherapeutic drugs. In this review, the recent articles about anti-tumor of ginsenosides were reviewed to promote the further development of anti-tumor therapy.
\end{abstract}

\section{Keywords}

Ginsenosides, Autophagy, Apoptosis, Proliferation, Metastasis

\section{Introduction}

Tumor is a life-threatening disease that affects human health, and both the incidence and mortality are very high [1]. At present, that surgery, radiotherapy and chemotherapy are the most commonly used ways of treatment for tumor. However, conventional chemotherapy has a lot of side effects due to its toxicity, and natural products with low side effects drugs are expected as alternative choice for tumor treatment [2]. Ginseng is derived from the root or rhizome of $P$. ginseng

*Authors contributed equally.

\#Corresponding authors. 
C.A. Meyer, which has become one of the most commonly used alternative herbal medicines all over the world, and it has been widely and extensively used in China for medicinal purposes for thousands of years due to its rich content of saponins [3]. Ginsenosides are a class of triterpenoid saponins primarily found in the plant genus Panax, which has a wide variety of biological effects including cardio-protector, neuro-protector, anti-cancer, vasodilating, antioxidant, anti-diabetic activities and hepatoprotective effects [4]. Ginsenosides include many monomer components, such as Rg3, Rh2, Rh4, Rg2, Rg5, etc. The mechanisms of anti-tumor effects of ginsenosides are discussed in detail in this review. Ginsenosides can inhibit tumor cells by suppressing proliferation and metastasis, and promoting apoptosis. In addition, ginsenosides can enhance sensitivity to conventional chemotherapeutic drugs, summarized in Table 1.

\section{Anti-Proliferation}

Proliferation plays an important role in the occurrence and development of tumor. Recent studies showed that ginsenoside can inhibit tumor by inhibiting cell proliferation.

\subsection{Ginsenoside Rg3}

Ham et al. [5] showed that Rg3 up-regulated tumor-related genes through alteration of epigenetic methylation levels, thereby inhibiting the growth of breast cancer cells. Rg3 down-regulated hypermethylated TRMT1L, PSMC6 and NOX4, and up-regulated methylated ST3GAL4, RNLS and KDM5A. Yang et al. [6] found that ginsenoside $\mathrm{Rg} 3$ inhibited the proliferation of colorectal cancer SW-480 cells by down-regulating the transcriptional activity of C/EBP beta NF-kappaB. Sun et al. [7] found that ginsenoside Rg3 inhibited the proliferation of Lewis lung cancer (LLC) cells by reducing ROS and down-regulating the expression of cyclin and cyclin dependent kinase. Shan et al. [8] showed that ginsenoside Rg3 can inhibit malignant melanoma by inducing G0/G1 cell cycle arrest, reducing histone deacetylase 3 (HDAC3) and up-regulating p53 acetylation. In a further study, Shan et al. [9] pointed out that ginsenoside Rg3 prevented the growth of melanoma through deactivation of EGFR/MAPK pathway mediated by decreased FUT4/LeY expression. In pancreatic cancer, ginsenoside Rg3 enhanced erotinib-induced apoptosis by increased the expression levels of caspase-3, 9 and cleaved PARP, and reduced the expression levels of p-EGFR, p-PI3K, and p-AKT. Therefore, ginsenoside Rg3 could enhance the role of erotinib on proliferation suppression and apoptosis induction via down-regulating the EGFR/PI3K/AKT pathway [10].

\subsection{Ginsenoside Rh2}

Li et al. [11] found that ginsenoside Rh2 induced cell cycle arrest by down-regulated cyclin dependent kinase 4 and cyclin $\mathrm{D}$, and significantly reduced the level of phosphorylated AKT. Therefore, ginsenoside Rh2 inhibited proliferation of 
Table 1. The anti-tumor effects and mechanisms of ginsenosides.

\begin{tabular}{|c|c|c|c|c|c|}
\hline $\begin{array}{l}\text { Anti-tumor } \\
\text { function }\end{array}$ & $\begin{array}{l}\text { Cancer } \\
\text { types }\end{array}$ & ginsenosides & cells or tissues & Mechanisms & Ref. \\
\hline \multirow{11}{*}{ anti-proliferation } & breast cancer & Rg3 & breast cancer cells & $\begin{array}{l}\text { up-regulated tumor-related genes through alteration of } \\
\text { epigenetic methylation levels down-regulated } \\
\text { hypermethylated TRMT1L, PSMC6 and NOX4, } \\
\text { up-regulated methylated ST3GAL4, RNLS and KDM5A }\end{array}$ & {$[5]$} \\
\hline & colorectal cancer & Rg3 & SW-480 cells & $\begin{array}{l}\text { down-regulating the transcriptional activity of C/EBP beta } \\
\text { NF-kappaB }\end{array}$ & {$[6]$} \\
\hline & Lewis lung cancer & Rg3 & lung cancer cells & $\begin{array}{l}\text { reducing ROS and down-regulating the expression of cyclin } \\
\text { and cyclin dependent kinase }\end{array}$ & [7] \\
\hline & $\begin{array}{l}\text { malignant } \\
\text { melanoma }\end{array}$ & Rg3 & $\begin{array}{l}\text { malignant } \\
\text { melanoma cells }\end{array}$ & $\begin{array}{l}\text { inducing G0/G1 cell cycle arrest, reducing histone deacetylase } \\
3 \text { (HDAC3) and up-regulating p } 53 \text { acetylation }\end{array}$ & {$[8]$} \\
\hline & melanoma & Rg3 & melanoma cells & $\begin{array}{l}\text { deactivation of EGFR/MAPK pathway mediated by decreased } \\
\text { FUT4/LeY expression }\end{array}$ & [9] \\
\hline & pancreatic cancer & Rg3 & $\begin{array}{l}\text { pancreatic } \\
\text { cancer cells }\end{array}$ & $\begin{array}{l}\text { increased the expression levels of caspase- } 3,9 \text { and cleaved } \\
\text { PARP, down-regulating the EGFR/PI3K/AKT pathway, } \\
\text { reduced the expression levels of p-EGFR, p-PI3K, and p-AKT }\end{array}$ & [10] \\
\hline & glioma & $\mathrm{Rh} 2$ & $\begin{array}{l}\text { human A172 } \\
\text { glioma cell }\end{array}$ & $\begin{array}{l}\text { regulating CDK4/CyclinD complex and AKT, down-regulated } \\
\mathrm{CDK} 4 \text { and cyclin D, reduced the level of phosphorylated AKT }\end{array}$ & [11] \\
\hline & lung cancer & $\mathrm{Rh} 2$ & H1299 cells & $\begin{array}{l}\text { induced ROS mediated endoplasmic reticulum } \\
\text { stress-dependent apoptosis, and up-regulated the expression } \\
\text { of activated transcription factor } 4 \text { (ATF4), CCAAT/enhanced } \\
\text { binding protein homologous protein (CHOP), and caspase- } 4\end{array}$ & [12] \\
\hline & prostate cancer & $\mathrm{Rh} 2$ & $\begin{array}{l}\text { prostate } \\
\text { cancer cells }\end{array}$ & $\begin{array}{l}\text { inhibiting microrna-4295, activates the cell cycle inhibitor } \\
\text { p21 (CDKN1A) }\end{array}$ & [14] \\
\hline & colorectal cancer & Rp1 & $\begin{array}{l}\text { colorectal cancer } \\
\text { LoVo cells }\end{array}$ & up-regulate apolipoprotein apo-a1 & [15] \\
\hline & breast cancer & Rp1 & $\begin{array}{c}\text { breast } \\
\text { cancer cells }\end{array}$ & inhibit the Akt/mTOR/P70S6 kinase signaling pathway. & [16] \\
\hline \multirow{7}{*}{ Pro-apoptosis } & lung cancer & Rg3 & $\begin{array}{l}\text { Lewis lung cancer } \\
\quad \text { (LLC) cells }\end{array}$ & $\begin{array}{l}\text { regulating apoptosis-related proteins, such as Bcl-2, Bax, } \\
\text { PARP-1, and lysed caspase- } 3\end{array}$ & [7] \\
\hline & lung cancer & Rg3 & $\begin{array}{l}\text { non-small cell } \\
\text { lung cancer } \\
\text { (NSCLC) cells }\end{array}$ & $\begin{array}{l}\text { up-regulated the pro-apoptotic protein Bax, down-regulated } \\
\text { the anti-apoptotic protein } \mathrm{Bcl}-2 \text {, thereby activating caspase- } 3 \text {. }\end{array}$ & [17] \\
\hline & gastric cancer & Rg3 & $\begin{array}{c}\text { gastric } \\
\text { cancer cells }\end{array}$ & $\begin{array}{l}\text { up-regulated the expression of SP1, activated caspase } 3,8,9 \\
\text { and PARP, down-regulated HSF1 }\end{array}$ & [18] \\
\hline & $\begin{array}{l}\text { human } \\
\text { osteosarcoma }\end{array}$ & Rg3 & $\begin{array}{l}\text { osteosarcoma } \\
\text { cell lines }\end{array}$ & $\begin{array}{l}\text { reduced the protein expression of Bcl2, repressed } \\
\text { PI } 3 \text { K/AKT/mTOR signaling pathway and increased the } \\
\text { expression of lysed caspase } 3\end{array}$ & [19] \\
\hline & ovrian cancer & Rg3 & HO-8910 cells & $\begin{array}{l}\text { suppression of the PI } 3 \mathrm{~K} / \text { Akt pathway, reducing the expression } \\
\text { of caspase- } 3 \text { and caspase- } 9\end{array}$ & [20] \\
\hline & breast cancer & $\mathrm{Rh} 4$ & McF-7 cells & $\begin{array}{l}\text { down-regulating Bcl-2, up-regulating Bax, and activating } \\
\text { caspase- } 8,-3 \text { and PARP }\end{array}$ & [21] \\
\hline & colorectal cancer & $\mathrm{Rh} 4$ & $\begin{array}{c}\text { colorectal } \\
\text { cancer cells }\end{array}$ & activating the $\mathrm{ROS} / \mathrm{JNK} / \mathrm{p} 53$ pathway & [22] \\
\hline
\end{tabular}




\section{Continued}

\begin{tabular}{|c|c|c|c|c|c|}
\hline & colorectal cancer & $\mathrm{Rh} 2$ & $\begin{array}{l}\text { HCT116 and } \\
\text { SW480 cells }\end{array}$ & $\begin{array}{l}\text { induce the caspase-mediated apoptosis, activated the p53 } \\
\text { pathway, increasing the level of pro-apoptotic protein Bax } \\
\text { and reducing the level of anti-apoptotic protein Bcl-2 }\end{array}$ & [23] \\
\hline & prostate cancer & $\mathrm{Rh} 2$ & DU145 cells & $\begin{array}{l}\text { up-regulating the expression of PPAR-delta and p-STAT3, } \\
\text { induction OF ROS/superoxide }\end{array}$ & [25] \\
\hline \multirow{6}{*}{ autophagy } & breast cancer & $\operatorname{Rg} 3$ & $\begin{array}{c}\text { breast } \\
\text { cancer cells }\end{array}$ & $\begin{array}{l}\text { decreased P62 levels, increased generation of LC3-II cleaved } \\
\text { from LC3-I }\end{array}$ & [29] \\
\hline & ovarian cancer & $\operatorname{Rg} 3$ & SKOV3 cells & increasing the levels of LC3-II, Atg5, and Atg7 & [28] \\
\hline & colorectal cancer & $\mathrm{Rh} 4$ & $\begin{array}{l}\text { colorectal } \\
\text { cancer cells }\end{array}$ & $\begin{array}{l}\text { activating ROS/JNK/p53 pathway, increased the } \\
\text { Beclin } 1 \text { levels, increase the expression of Atg-7 and LC3-II, } \\
\text { promote the autophagy }\end{array}$ & [22] \\
\hline & breast cancer & $\operatorname{Rg} 2$ & MCF-7 cells & $\begin{array}{l}\text { Increased p53 levels by transcriptional activation of GR, } \\
\text { activated TSC } 1 \text { and TSC } 2 \text {, phosphorylated AMPK, } \\
\text { inhibited the mTOR pathway, and increased autophagy }\end{array}$ & [32] \\
\hline & breast cancer & $\operatorname{Rg} 5$ & $\begin{array}{c}\text { breast } \\
\text { cancer cells }\end{array}$ & $\begin{array}{l}\text { inhibiting P13K/AKT/mTOR pathway, decreased P } 62 \text { levels, } \\
\text { increased Atg5, Atg7, Atg12, accelerated the LC3-I to LC3-II } \\
\text { transformation }\end{array}$ & [33] \\
\hline & $\begin{array}{l}\text { non-small-cell } \\
\text { cancer }\end{array}$ & CK & $\begin{array}{l}\text { non-small-cell } \\
\text { cancer cells }\end{array}$ & $\begin{array}{l}\text { induced generation of LC3-II cleaved from LC3-I, and } \\
\text { decreased the P62 levels }\end{array}$ & [34] \\
\hline \multirow{11}{*}{ Anti-metasis } & breast cancer & Rg3 & $\begin{array}{l}\text { MDA-MB-231 } \\
\text { cells }\end{array}$ & inhibits CXCR4 expression and & [37] \\
\hline & ovarian cancer & $\operatorname{Rg} 3$ & SKOV3 cells & $\begin{array}{l}\text { down-regulating the expression of VEGF mRNA and protein, } \\
\text { reducing microvascular density and blocking angiogenesis }\end{array}$ & [38] \\
\hline & ovarian cancer & $\operatorname{Rg} 3$ & SKOV3 cells & reduction of MMP-9 expression, promote the invasion & [39] \\
\hline & breast cancer & $\mathrm{Rd}$ & $4 \mathrm{~T} 1$ cells & $\begin{array}{l}\text { decreasing miR-18a-mediated Smad } 2 \text { expression, } \\
\text { decaying migration }\end{array}$ & [56] \\
\hline & hepatocellr cancer & $\mathrm{Rd}$ & HepG2 cells & $\begin{array}{l}\text { down-regulating the expression of MMP-1, MMP-2, and } \\
\text { MMP-7 by inhibiting ERK and MAPK signaling pathways }\end{array}$ & [57] \\
\hline & melanoma cancer & Rp1 & B16F10 Cells & $\begin{array}{l}\text { down-regulating the expression of beta1-integrin (CD29), } \\
\text { inhibiting the formation of blood vessels }\end{array}$ & [63] \\
\hline & $\begin{array}{l}\text { glioblastoma } \\
\text { multiforme }\end{array}$ & $\mathrm{Rh} 2$ & U251 cells & inhibit AKT mediated MMP13 activation & [58] \\
\hline & colerectal cancer & $20(\mathrm{~S})-\mathrm{Rh} 2$ & CRC cells & $\begin{array}{l}\text { down-regulatingIL-6-induced signal transducer, STAT3, } \\
\text { MMPs (MMP-1, -2, and -9) }\end{array}$ & {$[60]$} \\
\hline & colorectal cancer & $20(S)-\operatorname{Rg} 3$ & $\begin{array}{l}\text { SW280 and } \\
\text { SW620 cells }\end{array}$ & $\begin{array}{l}\text { inhibited the expression of fatty acid synthetase and } \\
\text { histone } \mathrm{H} 4\end{array}$ & [10] \\
\hline & colerectal cancer & $\mathrm{Rb} 2$ & $\begin{array}{l}\text { HT29 and } \\
\text { SW620 cells }\end{array}$ & $\begin{array}{l}\text { down-regulating stemness and Epithelial-mesenchymal } \\
\text { transition (EMT)-related genes via the EGFR/SOX2 } \\
\text { signaling axis }\end{array}$ & [61] \\
\hline & malignant gliomas & Rh1 & $\begin{array}{l}\text { U87MG and } \\
\text { U373MG cells }\end{array}$ & $\begin{array}{l}\text { inhibited mRNA expressions and promoter activity, } \\
\text { down-regulating the expression of MMP-1, }-3 \text {, and }-9\end{array}$ & [59] \\
\hline \multirow[b]{2}{*}{$\begin{array}{l}\text { Inhibiting } \\
\text { EMT }\end{array}$} & lung cancer & $20(\mathrm{R})-\mathrm{Rg} 3$ & A549 cells & $\begin{array}{l}\text { suppressing the expression of E-cadherin and vimentin by } \\
\text { inhibiting TGF- } B 1 \text { activation }\end{array}$ & [46] \\
\hline & liver cancer & Rg1 & HepG2 cells & $\begin{array}{l}\text { increased the expression of E-cadherin and inhibited the } \\
\text { expression of the mesenchymal phenotype marker vimentin } \\
\text { by inhibiting TGF- } \beta 1\end{array}$ & [54] \\
\hline
\end{tabular}




\section{Continued}

\begin{tabular}{|c|c|c|c|c|c|}
\hline & ovarian cancer & $\operatorname{Rg} 1$ & SKOV3 cells & $\begin{array}{l}\text { recovered the expression of E-cadherin and attenuated } \\
\text { expression of vimentin by regulating NF- } \mathrm{kB} \text { pathway }\end{array}$ & [55] \\
\hline & ovarian cancer & $\mathrm{Rb} 1$ & $\begin{array}{l}\text { SKOV3 and } \\
3 \mathrm{AO} \text { cells }\end{array}$ & $\begin{array}{l}\text { by down-regulating the expression of miR-25, E-cadherin } \\
\text { transcriptional activator EP } 300 \text { is overexpressed, } \\
\text { thus increasing E-cadherin level }\end{array}$ & [62] \\
\hline & breast cancer & CK & MCF-7 cells & $\begin{array}{l}\text { decreasing N-cadherin and vimentin, and increase level of } \\
\text { E-cadherin through inhibition the activation of PI3K/Akt } \\
\text { pathway }\end{array}$ & $\begin{array}{l}{[66]} \\
{[67]}\end{array}$ \\
\hline \multirow{8}{*}{$\begin{array}{l}\text { Chemotherapy } \\
\text { sensibilization }\end{array}$} & lung cancer & Rg3 & $\begin{array}{l}\text { hypoxic lung } \\
\text { cancer cell }\end{array}$ & $\begin{array}{l}\text { blocking of NF- } \mathrm{kB} \text { mediated EMT and stemness, reduced the } \\
\text { toxicity induced by cisplatin }\end{array}$ & $\begin{array}{l}{[70]} \\
{[71]} \\
{[72]}\end{array}$ \\
\hline & lung cancer & $\operatorname{Rg} 3$ & lung cancer cells & $\begin{array}{l}\text { attenuated cisplatin resistance and increased chemosensitivity } \\
\text { by down-regulating PD-L1 and resuming immune }\end{array}$ & [10] \\
\hline & colon cancer & $\operatorname{Rg} 3$ & colon cancer cells & $\begin{array}{l}\text { enhanced the sensitivity of cisplatin by reducing the basal level } \\
\text { of nuclear factor erythroid 2-related factor2-mediated heme } \\
\text { oxygenase-1/NAD(P)H quinone oxidoreductase-1 }\end{array}$ & [13] \\
\hline & pancreatic cancer & $\operatorname{Rg} 3$ & $\begin{array}{l}\text { pancreatic } \\
\text { cancer cells }\end{array}$ & $\begin{array}{l}\text { enhances the anti-proliferative activity of erlotinib by } \\
\text { downregulation of EGFR/PI3K/Akt signaling pathway By } \\
\text { downregulation of EGFR/PI3K/Akt signaling pathway }\end{array}$ & [75] \\
\hline & hepatocellar cancer & Rg3 & $\begin{array}{l}\text { hepatocellular } \\
\text { carcinoma cells }\end{array}$ & $\begin{array}{l}\text { sensitize TRAIL-induced cell death CHOP-mediated DR5 } \\
\text { upregulation }\end{array}$ & [59] \\
\hline & ovarian cancer & $\mathrm{Rb} 1$ & $\begin{array}{l}\text { ovarian } \\
\text { cancer cells }\end{array}$ & $\begin{array}{l}\text { promote sensitivity of cisplatin and paclitaxel by suppressing } \\
\text { the Wnt/ } \beta \text {-catenin signaling and EMT }\end{array}$ & [76] \\
\hline & lung cancer & $\mathrm{Rd}$ & $\begin{array}{l}\text { lung } \\
\text { cancer cells }\end{array}$ & significant sensitization was achieved by inhibiting NRF2 & [79] \\
\hline & esophageal cancer & Ro & $\begin{array}{l}\text { esophageal } \\
\text { cancer cells }\end{array}$ & $\begin{array}{l}\text { delayed DNA repair and the accumulation of DNA damage } \\
\text { by potentiating 5-Fu cytotoxicity via delaying CHEK1 } \\
\text { (checkpoint kinase 1) degradation and downregulating } \\
\text { DNA replication process }\end{array}$ & [28] \\
\hline
\end{tabular}

human A172 glioma cell by regulating CDK4/CyclinD complex and AKT. In lung cancer H1299 cells, Ge et al. [12] found that ginsenoside Rh2 induced ROS mediated endoplasmic reticulum stress-dependent apoptosis, and up-regulated the expression of activated transcription factor 4 (ATF4), CCAAT/enhanced binding protein homologous protein (CHOP), and caspase-4, thereby inhibiting cell proliferation. Yong et al. [13] proved that ginsenoside Rh2 significantly inhibited the proliferation of nasopharyngeal carcinoma CSCs in vitro, promoted apoptosis, and reduced the expression of IL-6. Gao et al. [14] indicated that ginsenoside $\mathrm{Rh} 2$ inhibited the growth of prostate cancer cells by inhibiting microrna-4295, which activates the cell cycle inhibitor p21 (CDKN1A).

\subsection{Other Ginsenosides}

Ginsenoside Rp1 is a new ginsenoside derived from ginsenoside Rk1. Kim et al. [15] found that ginsenoside Rp1 can up-regulate apolipoprotein apo-a1 in colorectal cancer LoVo cells, strongly inhibiting cell proliferation and promoting cell apoptosis. Zhang et al. [16] found that ginsenoside $\mathrm{Rd}$ can inhibit the prolifera- 
tion and induce apoptosis of breast cancer cells, and inhibit the Akt/mTOR/P70S6 kinase signaling pathway.

\section{Pro-Apoptosis}

Apoptosis refers to the spontaneous and orderly death of cells controlled by genes to maintain the stability of the internal environment. Different from cell necrosis, cell apoptosis is not a passive process, but an active process, which involves the activation, expression and regulation of a series of genes. It is not a phenomenon of self-injury under pathological conditions, but a death process that actively strives for better adaptation to the living environment. With the development of scientific research, it has been found that inadequate apoptosis plays a key role in the occurrence and development of tumor cells.

\subsection{Ginsenoside Rg3}

Sun et al. [7] found Rg3 induced apoptosis of Lewis lung cancer (LLC) cells by regulating apoptosis-related proteins, such as Bcl-2, Bax, PARP-1, and lysed caspase-3. Dai et al. [17] demonstrated that the combined use of ginsenoside Rg3 and gefitinib can up-regulated the pro-apoptotic protein Bax and down-regulated the anti-apoptotic protein $\mathrm{Bcl}-2$, thereby activating caspase- 3 and promoting the apoptosis of non-small cell lung cancer (NSCLC) cells. Aziz F.'s et al. [18] pointed out that ginsenoside Rg3 up-regulated the expression of specific protein 1 (SP1) and down-regulated heat shock factor 1 (HSF1) to inhibit the expression of brown alginase transferase IV (FUT4), and activated caspase-3, -8, -9 and PARP to promote the apoptosis of gastric cancer cells. Li et al. [19] found that ginsenoside $\mathrm{Rg} 3$ reduced the protein expression of Bcl2 and repressed PI3K/AKT/mTOR signaling pathway in human osteosarcoma cell lines (mg-63, u-2os and saos-2), and increased the expression of lysed caspase3. Therefore, Rg3 induced apoptosis of human osteosarcoma cell lines. In addition, ginsenoside 20(S) - Rg3 can also induce apoptosis of ovarian cancer HO-8910 cells through suppression of the PI3K/Akt pathway. Concordantly, Wang et al. [20] found that 20(S)-ginsenoside Rg3 reduced the activity of ovarian cancer HO-8910 cells in dose- and time-dependent manners, and induced apoptosis. Apoptosis induction was due to down-regulation of phosphatidylinositol 3-kinase (PI3K)/Akt family protein and apoptosis-inhibiting protein (IAP) family protein, and up-regulation of the expression of caspase- 3 and caspase- 9 .

\subsection{Ginsenoside Rh4}

Duan et al. [21] found that ginsenoside Rh4 can promote apoptosis of breast cancer McF-7 cells by down-regulating Bcl-2, up-regulating Bax, and activating caspase-8, -3 and PARP. Another study indicated that Rh4 increased the accumulation of reactive oxygen species (ROS), thereby activating the JNK-p53 pathway [22]. Reactive oxygen scavenging agents, JNK and p53 inhibitors can significantly reduce $\mathrm{Rh} 4$-induced apoptosis, suggesting that $\mathrm{Rh} 4$ can trigger 
apoptosis by activating the ROS/JNK/p53 pathway in colorectal cancer cells.

\subsection{Ginsenoside Rh2}

Li et al. [23] confirmed that in colorectal cancer HCT116 and SW480 cells, ginsenoside Rh2 can induce the caspase-mediated apoptosis of colorectal cancer cells. Rh2 activated the p53 pathway, significantly increasing the level of pro-apoptotic protein Bax and reducing the level of anti-apoptotic protein Bcl-2. It was reported that ginsenoside $\mathrm{Rh} 2$ inhibited the proliferation of gastric cancer SGC-7901 Side Population cells in a dose-dependent manner. Rh2 arrested cells at G1/G0 phase, followed by stimulation of apoptosis through up-regulation of Bax and down-regulation of Bcl-2 [24]. Wu et al. [25] found that ginsenoside $\mathrm{Rh} 2$ induced apoptosis of prostate cancer DU145 cells by up-regulating the expression of PPAR-delta, which was related to the up-regulation of p-STAT3 and induction OF ROS/ superoxide.

\subsection{Ginsenoside F2}

Ginsenoside F2 is the potential bioactive metabolite of main ginsenosides. Mao [26] indicated that Ginsenoside F2 induced ROS accumulation, decreased mitochondrial transmembrane potential (MTP), stimulated the release of cytochrome c, and induced caspase-dependent apoptosis. The regulation of ASK-1/JNK pathway also contributed to apoptosis. Results suggested that Ginsenoside F2 induced apoptosis by inducing ROS accumulation and activating ASK-1/JNK signaling pathway.

\section{Ginsenoside Inhibits Tumor Cells by Autophagy}

Autophagy is an intracellular degradation pathway that transports damaged, deformed, aging or dysfunctional proteins and organelles in cells to lysosomes for digestion and degradation, so as to realize the metabolic needs of cells and the renewal of organelles. It has been found that autophagy plays a very important role in the genesis and development of tumors, which gradually attracts people's wide attention. Recent studies show that ginsenoside can inhibit tumor cells through autophagy.

\subsection{Ginsenoside Rg3}

The effect of ginsenosides on autophagy is controversial. Reportedly, ginsenoside 20(S)-Rg3 (a type of $\mathrm{Rg} 3$ ginsenosides stereo isomer) inhibited autophagic flux by suppression of late-stage autophagosome maturation or degradation and eventually induced apoptosis in cervical cancer cells [5]. However, Zhang Y et al. [27] found that that ginsenoside Rg3 induced autophagy so as to inhibit breast cancer tumor growth in tumor-bearing mice, and its mechanism was associated with P13K/AKT/mTOR pathway, Rg3 decreased P62 levels, increased generation of LC3-II cleaved from LC3-I. Zheng et al. [28] showed that 20 (S)-ginsenosides Rg3 induced autophagy in ovarian cancer SKOV3 cells by increasing the levels of 
LC3-II, Atg5, and Atg7.

\subsection{Ginsenoside $\mathrm{Rh} 2, \mathrm{Rh} 4$}

Lv et al. [29] found that smith-4 can inhibit the phosphorylation of AKT/mTOR and reduce the activity of AKT/mTOR pathway to promote autophagy, while ginsenoside $\mathrm{Rh} 2$ can enhance this autophagy activity in vivo and in vitro to enhance the anti-melanoma efficacy of smith-4. Liu et al. [30] found that ginsenoside $\mathrm{Rh} 2$ promoted autophagy and apoptosis of $\mathrm{K} 562$ cells. Rh2 ginsenosides reduced the expression of HDAC6, promoted acetylation of Hsp90, and increased the expression of LC3-I, LC3-II, Beclin 1. Sarkar et al. [31] showed that increasing the acetylation of Hsp90 and decreasing the expression of Hsp90 would both cause autophagy and apoptosis of cells.

Wu et al. [22] et al. investigated the role of ginsenoside Rh4 in colorectal cancer cells (Caco 2, HCT116 cell) on growth inhibition, and they found that Rh4 promoted autophagy of colorectal cancer cells by activating ROS/JNK/p53 pathway. Rh4 promoted intracellular reactive oxygen species (ROS), which led to JNK phosphorylation and further promotes the p53 phosphorylation. Phosphorylated p53 increased the Beclin 1 levels, which can further increase the expression of Atg-7 and LC3- II so as to promote the autophagy, optimization inhibition of colon cancer cells growth.

\subsection{Ginsenoside Rg2, Rg5}

Chung et al. [32] found that in breast cancer MCF-7 cells, Rg2 can bind to glucocorticoid receptor (GR) as a glucocorticoid-like cellular mechanism. Rg2 increased p53 levels by transcriptional activation of GR, which activated the tuberous sclerosis complex 1 (TSC1) and TSC2, then phosphorylated AMPK and subsequently inhibited the mTOR pathway, and increased autophagy. Rg2 increased the levels of p-p53, p-AMPK, Atg-7, and LC3-II, while decreased the levels of $\mathrm{p} 62$.

Liu et al. [33] proved that ginsenoside $\mathrm{Rg} 5$ had a strong anti-tumor effect in human breast cancer cells. Rg5 promoted autophagy by inhibiting P13K/AKT/mTOR pathway, which decreased P62 levels, increased by Atg5, Atg7, Atg12, and accelerated the LC3-I to LC3-II transformation to promote autophagy.

$\mathrm{CK}$, the metabolite of ginsenoside, can increase the phosphorylation level of AMPK and reduce the phosphorylation level of mTOR, thereby promoting autophagy and promoting apoptosis. Chen et al. [34] found that CK treatment up-regulated the expression of Beclin 1 in non-small-cell cancer cells, induced generation of LC3-II cleaved from LC3-I, and decreased the P62 levels.

\section{Anti-Metastasis}

Tumor metastasis is the outcome of combined action of many factors, such as transfer signals, extracellular matrix, adhesion molecules, and hyaluronic acid receptor family, as well as genes related to angiogenesis [35]. 


\subsection{Ginsenoside Rg3}

It has been found that Chemokine CXC receptor 4 (CXCR4) plays an important role in metastasis by acting on the chemokine ligand CXCL12. [36] Chen et al. [37] demonstrated that ginsenoside Rg3 inhibited CXCR4 expression and CXCL12 (CXCR4 ligand) induced chemotaxis in cultured MDA-MB-231 cell, a highly metastatic cell line of breast cancer, thus inhibiting cancer cell migration. Pan et al. [38] found that ginsenoside Rg3 can inhibit the growth and metastasis of ovarian cancer cells by down-regulating the expression of VEGF mRNA and protein, reducing microvascular density and blocking angiogenesis. XU et al. [39] found that ginsenoside Rg3 can significantly inhibit the metastasis of ovarian cancer. The inhibitory effect was partly due to reduction of MMP-9 expression, which promoted the ovarian cancer SKOV3 cells to invade.

Lee et al. [40] investigated the effects of ginsenoside $20(\mathrm{~S})-\operatorname{Rg}(3)$ in colorectal cancer SW620 cells, and found that ginsenoside $20(S)-\operatorname{Rg}(3)$ inhibited the expression of fatty acid synthetase and histone $\mathrm{H} 4$, thus inhibiting the metastasis of SW620 cells.

The epithelial-mesenchymal transition (EMT) is a physiological and pathological phenomenon, characterized by the loss of typical epithelial characteristics and the acquisition of mesenchymal traits. [41] Studies have revealed that EMT contributes to cancer progression, invasion and migration in various types of cancer [42] [43]. In the process of EMT, the expression of E-cadherin, a membrane protein mediating the tight junction between epithelial cells, is downregulated, and the expression of connexin between mesenchymal cells, such as $\mathrm{N}$-cadherin and vimentin, is upregulated. [44] Tian et al. [45] found that Rg3 significantly up-regulated the mRNA levels of the E-cadherin, and down-regulated the mRNA levels of Snail, N-cadherin and Vimentin in NSCLC cells (A549, H1299 and H358 cells), thereby effectively preventing EMT process in dose- and time-dependent manners. Kim et al. [46] found that 20(R)-Rg3 inhibited the EMT by suppressing E-cadherin and vimentin expression in TGF-ß1-activated lung cancer A549 cells. Ting et al. [47] found that ginsenoside 20(S)-Rg3 potently blocked hypoxia-induced EMT of ovarian cancer cells in vitro and in vivo. They confirmed that 20(S)-Rg3 reduced the expression of hypoxia-inducible factor 1a (HIF-1a) by activating the ubiquitin-proteasome pathway to promote HIF-1a degradation. Decreased HIF-1a suppressed Snail transcription, leading to up-regulation of E-cadherin (the epithelial cell-specific marker) and down-regulation of vimentin (the mesenchymal cell-specific marker) under hypoxic conditions.

\subsection{Ginsenoside Rg1}

Transforming growth factor (TGF)- $\beta 1$ was found to be the main inducer of ETM [48] [49]. Ginsenoside Rg1, is one active and abundant components in ginseng, which has exerts anticancer properties [50] [51] [52] [53]. Yu et al. [54] found that TGF- $\beta 1$ could induce the expression of vimentin and decrease the 
expression of E-cadherin, which could make human liver cancer HepG2 cells behave as mesenchymal phenotype and significantly enhance the invasion and migration of cells. When treated with ginsenoside Rg1, Rg1 increased the expression of E-cadherin and inhibited the expression of the mesenchymal phenotype marker vimentin, showing a typical epithelial morphology. Therefore, ginsenoside Rg1 inhibited the invasion and migration of hepatocellular carcinoma HepG2 cells in vitro by inhibiting EMT. Concordantly, Dan et al. [55] found that treatment with ginsenoside $\mathrm{Rg} 1$ for $48 \mathrm{~h}$ in ovarian cancer cell SKOV3, the EMT morphology change induced by hypoxia was partially reversed. Rg1 recovered the expression of E-cadherin and attenuated expression of vimentin by regulating NF-KB pathway.

\subsection{Ginsenoside Rd}

Ginsenoside $\mathrm{Rd}$ is a kind of procyanidins found in ginseng ginseng saponin. Wang et al. [56] found that Rd treatment increased expression of Smad2 by down-regulating microRNA (miR)-18a in cultured $4 \mathrm{~T} 1$ cells and in tumors grown from inoculated $4 \mathrm{~T} 1$ cells. Smad2, a direct target of miR-18a, significantly induced attenuation of migration in $4 \mathrm{~T} 1$ cells.

Yoon et al. [57] showed that ginsengside inhibited migration and invasion of human hepatocellular cancer HepG2 cells by inhibiting ERK and MAPK signaling pathways, which reduced the expression of MMP-1, MMP-2 and MMP-7.

\subsection{Ginsenoside Rh2, Rh1}

Guan et al. [58] found that Rh2 reduced the invasiveness of glioblastoma cells in a dose-dependent manner by inhibiting AKT mediated MMP13 activation, assessed by wound healing test and Transwell assay. Jung et al. [59] showed that Rh1 inhibited the mRNA expressions of MMP-1, -3 and -9 in human malignant gliomas cells (U87MG and U373MG). Rh1 also inhibits promoter activity of MMP-1, -3, and -9. Further studies showed that Rh1 played an important role in inhibiting MAPK and PI3K/Akt signaling pathways and downstream transcription factors. Han et al. [60] found that ginsenoside 20(S)-Rh2 effectively inhibited the phosphorylation of signal transducers and transcriptional activator 3 (STAT3), as well as the expression of matrix metalloproteinases (MMPs), including MMP-1, -2 , and -9 , thereby inhibiting the metastasis of colorectal cancer cells.

\subsection{Ginsenoside Rb2, Rb1, Rp1}

Phi et al. [61] found that ginsenoside Rb2 inhibited CSC properties and EMT of HT29 SW620 cells, thereby inhibiting the transfer of CRC cells in vivo, which was achieved by inhibiting EGFR and its downstream signal pathways, SOX2 and Snail. Liu et al. [62] demonstrated that Rb1 downregulated the expression of miR-25, resulting in overexpression of E-cadherin transcriptional activator EP300, thus increasing E-cadherin level and inhibiting the hypoxia-induced 
EMT process in ovarian cancer SKOV3 and 3AO cells. Ginsenoside Rp1, a new type of ginseng saponin, was showed to play an anticancer role by inhibiting the adhesion of tumor cells and the formation of blood vessels, and by strongly inhibiting the cell activity and metastasis process. Park et al. proved that Rp1 inhibited human umbilical vein endothelial cells (HUVECs) tube formed, blocked HCT15 and A549 cell viability, and strongly inhibited the pulmonary metastasis of B16-F10 melanoma cells [63].

\subsection{Ginsenoside Compound K (CK)}

CK (20-O- $\beta$-d-glucopyranosyl-20(S)-protopanaxadiol) is an active metabolite that are synthesized by intestinal bacteria after oral administration of ginsenosides Rb1, Rb2, Rc and Rd. [64] It was found that CK increased the level of epithelial marker molecule Ecadherin, and reduced the level of mesenchymal markers $\mathrm{N}$-cadherin and vimentin in MCF-7 cells, indicating that $\mathrm{CK}$ inhibited the EMT process in MCF-7 cells [65]. The activation of PI3K/Akt signalling pathway may promote the occurrence of EMT in most tumour cells [66] [67]. Studies showed that CK inhibited the EMT in MCF-7 cells, which may be due to inhibition the activation of PI3K/Akt pathway [68], since it was clarified that CK could inhibit EMT by reducing the level of p-AKT [65]. Peng et al. [69] found that CK decreased $\mathrm{N}$-cadherin and increased E-cadherin in liver cancer HepG2 cells, indicating that CK inhibited the EMT process. Suppression of ERK and Akt signaling pathways was involved in this pharmacologic action.

\section{Sensitization to Chemotherapeutic Drugs}

Chemotherapy has been the mainstay of cancer treatment for the past several decades. As a result of the heterogeneity of the tumor cell population, the sensitivity of the different clones of the same cell related to the drug is different, and it is easy to produce the drug resistance to the chemotherapeutic agent. Therefore, it has become a new strategy of tumor chemotherapy to seek low toxic chemotherapeutic sensitizers to enhance the cytotoxicity of antineoplastic drugs or to change the resistance of tumor cells to chemotherapy in the future.

\subsection{Ginsenoside Rg3}

Wang et al. [70] [71] reported that ginsenoside Rg3 sensitized hypoxic lung cancer cells to cisplatin via blocking of NF- $\kappa$ B mediated EMT and stemness [72], and $\mathrm{Rg} 3$ also reduced the toxicity induced by cisplatin. Lee et al. [73] found that Rg3 enhanced the sensitivity of colon cancer cells to cisplatin by reducing the basal level of nuclear factor erythroid 2-related factor2-mediated heme oxygenase-1/NAD(P)H quinone oxidoreductase-1, and prevented normal tissue damage by scavenging cisplatin-induced intracellular ROS. Jiang et al. [10] showed that $\mathrm{Rg} 3$ attenuated cisplatin resistance and increased chemosensitivity in lung cancer by down-regulating PD-L1 and resuming immune. Tang et al. [74] found that Rg3 could strengthen the cytotoxicity of 5-Fluorouracil and oxalip- 
latin against orthotopic xenografts in vivo in colorectal cancer by downregulating the levels of $\mathrm{B} 7-\mathrm{H} 1$ and $\mathrm{B} 7-\mathrm{H} 3$, predictors of adverse clinical outcomes in CRC. Jiang et al. [75] found Ginsenoside Rg3 enhances the anti-proliferative activity of erlotinib in pancreatic cancer cell lines by downregulation of EGFR/PI3K/Akt signaling pathway. Lee [59] et al. found that ginsendoside Rg3 sensitize TRAIL-induced cell death by via CHOP-mediated DR5 upregulation in human hepatocellular carcinoma cells.

\subsection{Ginsenoside $\mathrm{Rb} 1, \mathrm{Rh} 2, \mathrm{Rp} 1, \mathrm{Rd}$, Ro}

Deng et al. [76] proved that ginsenoside Rb1 exerted strong cytotoxicity to tumor stem cells. Rb1 and its metabolites can effectively inhibit the growth of ovarian cancer stem cells, promoting cells more sensitive to clinical-related doses of chemotherapeutic drugs, such as cisplatin and paclitaxel. The mechanism is that by suppressing the $\mathrm{Wnt} / \beta$-catenin signaling and EMT. Studies delivered by $\mathrm{Na}-$ kata indicated that ginsenoside $\mathrm{Rh} 2$ combined with cisplatin can enhance the therapeutic effect in ovarian cancer, since Rh2 sensitized ovarian cancer cell to cisplatin in vitro and in vivo [77]. The membrane transporter MDR-1, located on the lipid rafts of the plasma membrane, and increased MDR-1 activity is an important contributor to multidrug resistance. Yun et al. [78] found that ginsenoside Rp1 repressed MDR-1 activity by redistributing lipid rafts, which reversed resistance to anti-tumor drugs, including doxorubicin. Chian found that GS-Rd significantly sensitized A549/DDP cells to therapeutic drugs by inhibiting NRF2 which could develop multidrug resistance [79]. Zheng K et al. [28] found that ginsenoside Ro potentiates 5-Fu cytotoxicity via delaying CHEK1 (checkpoint kinase 1) degradation and downregulating DNA replication process, resulting in the delayed DNA repair and the accumulation of DNA damage.

\section{Conclusions}

Malignant tumors are in the forefront of mortality and morbidity in malignant diseases, which seriously affects the health of people. Therefore, it is very important to explore the effective treatment for malignant tumors. At present, surgery and radiotherapy combined with chemotherapy are mainly used in clinic, the main chemotherapeutic drugs are cisplatin, paclitaxel and so on. However, multi-drug resistance, toxic reactions and adverse reactions greatly limit its clinical efficacy. Therefore, there is a need to explore more ideal drugs for the treatment of tumors.

To sum up, a large number of feasibility trials have shown that ginsenosides can not only interfere with cancer by targeting several molecules and pathways involved in cancer development, but also do little harm to normal cells in the body. Moreover, when these plant extracts are used in combination with chemotherapeutic drugs, it is observed a stronger anti-cancer effect and less toxic than using chemotherapy alone. More importantly, it can reverse the multi-drug resistance of chemotherapeutic drugs. The antitumor effects of ginsenosides and signal pathways are shown in Figure 1, including anti-proliferation, pro-apoptosis, 


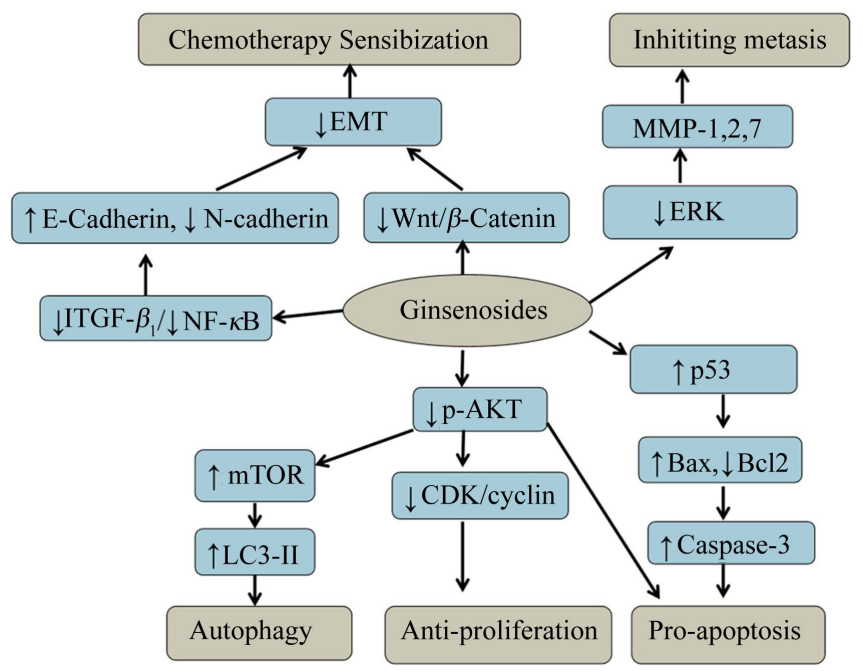

Figure 1. This figure shows the antitumor effects of ginsenosides and signal pathways.

anti-metasis, and chemotherapy sensibilization. Therefore, it is of great significance to further study the pharmacological effects of total ginsenosides and their monomers. It can be predicted that with the study of the deep human system of ginsenosides, many aspects of their biological effects will gradually be revealed. The combination of ginsenoside and chemotherapeutic drugs may be a more ideal strategy for the treatment of tumors in clinical studies in future.

\section{Acknowledgements}

This work was supported by the National Natural Science Foundation of China (81602303), and the National College Students' Innovative and Entrepreneurial Training Program (201910489014).

\section{Authors' Contributions}

Jing $\mathrm{Wu}$, Shuaishuai $\mathrm{Niu}$, and $\mathrm{Li}$ Guan initiated the topic and wrote the manuscript. Ying Xiang revised the manuscript. All authors read and approved the final manuscript.

\section{Conflicts of Interest}

The authors declared that there was no conflict of interests.

\section{References}

[1] Siegel, R.L., Miller, K.D. and Jemal, A. (2020) Cancer Statistics, 2020. CA: A Cancer Journal for Clinicians, 70, 7-30. https://doi.org/10.3322/caac.21590

[2] Farzaei, M.H., Bahramsoltani, R. and Rahimi, R. (2016) Phytochemicals as Adjunctive with Conventional Anticancer Therapies. Current Pharmaceutical Design, 22, 4201-4218. https://doi.org/10.2174/1381612822666160601100823

[3] Helms, S. (2004) Cancer Prevention and Therapeutics: Panax Ginseng. Alternative Medicine Review, 9, 259-274. 
[4] Leung, K.W. and Wong, A.S. (2010) Pharmacology of Ginsenosides: A Literature Review. Chinese Medicine, 5, 20. https://doi.org/10.1186/1749-8546-5-20

[5] Juyeon, H., Seungyeon, L., Hyunkyung, L., Dawoon, J., Sungbin, P. and Jung, K.S. (2018) Genome-Wide Methylation Analysis Identifies NOX4 and KDM5A as Key Regulators in Inhibiting Breast Cancer Cell Proliferation by Ginsenoside Rg3. American Journal of Chinese Medicine, 46, 1333-1355.

[6] Zhao, L., Liu, S., Xu, J., Li, W., Duan, G., Wang, H., et al. (2017) A New Molecular Mechanism Underlying the EGCG-Mediated Autophagic Modulation of AFP in HepG2 Cells. Cell Death \& Disease, 8, e3160. https://doi.org/10.1038/cddis.2017.563

[7] Sun, H.Y., Lee, J.H., Han, Y.S., Yoon, Y.M. and Sang, H.L. (2016) Pivotal Roles of Ginsenoside Rg3 in Tumor Apoptosis through Regulation of Reactive Oxygen Species. Anticancer Research, 36, 4647. https://doi.org/10.21873/anticanres.11015

[8] Shan, X., Fu, Y.S., Aziz, F., Wang, X.Q., Yan, Q. and Liu, J.W. (2014) Ginsenoside Rg3 Inhibits Melanoma Cell Proliferation through Down-Regulation of Histone Deacetylase 3 (HDAC3) and Increase of p53 Acetylation. PLOS ONE, 9, e115401. https://doi.org/10.1371/journal.pone.0115401

[9] Shan, X., et al. (2015) Ginsenoside Rg3-Induced EGFR/MAPK Pathway Deactivation Inhibits Melanoma Cell Proliferation by Decreasing FUT4/LeY Expression. International Journal of Oncology, 46, 1667-1676. https://doi.org/10.3892/ijo.2015.2886

[10] Jiang, Z., Yang, Y., Yang, Y., Zhang, Y., Yue, Z., Pan, Z., et al. (2017) Ginsenoside Rg3 Attenuates Cisplatin Resistance in Lung Cancer by Downregulating PD-L1 and Resuming Immune. Biomedicine \& Pharmacotherapy, 96, 378-383.

https://doi.org/10.1016/j.biopha.2017.09.129

[11] Hu, Q., Li, L., Zou, X., Xu, L. and Yi, P. (2018) Berberine Attenuated Proliferation, Invasion and Migration by Targeting the AMPK/HNF4alpha/WNT5A Pathway in Gastric Carcinoma. Frontiers in Pharmacology, 9, 1150. https://doi.org/10.3389/fphar.2018.01150

[12] Ge, G., Yan, Y. and Cai, H. (2017) Ginsenoside Rh2 Inhibited Proliferation by Inducing ROS Mediated ER Stress Dependent Apoptosis in Lung Cancer Cells. Biological \& Pharmaceutical Bulletin, 40, 2117-2124. https://doi.org/10.1248/bpb.b17-00463

[13] Liu, Y. (2016) nhibiting effect of ginsenoside Rh2 in vitro on nasopharynx cancer CSCs proliferation. Journal of Hainan Medical University.

[14] Gao, Q. and Zheng, J. (2018) Ginsenoside Rh2 Inhibits Prostate Cancer Cell Growth through Suppression of microRNA-4295 That Activates CDKN1A. Cell Proliferation, 51, e12438. https://doi.org/10.1111/cpr.12438

[15] Kim, M.Y., Yoo, B.C. and Cho, J.Y. (2014) Ginsenoside-Rp1-Induced Apolipoprotein A-1 Expression in the LoVo Human Colon Cancer Cell Line. Journal of Ginseng Research, 38, 251-255. https://doi.org/10.1016/j.jgr.2014.06.003

[16] Zhang, E., Shi, H., Yang, L., Wu, X. and Wang, Z. (2017) Ginsenoside Rd Regulates the Akt/mTOR/p70S6K Signaling Cascade and Suppresses Angiogenesis and Breast Tumor Growth. Oncology Reports, 38, 359-367. https://doi.org/10.3892/or.2017.5652

[17] Dai, Y., Wang, W., Sun, Q. and Tuohayi, J. (2018) Ginsenoside RG3 Promotes the Antitumor Activity of Gefitinib in Lung Cancer Cell Lines. Experimental and Therapeutic Medicine, 17, 953-959. https://doi.org/10.3892/etm.2018.7001

[18] Aziz, F., Wang, X.Q., Liu, J.W., et al. (2016) Ginsenoside Rg3 Induces 
FUT4-Mediated Apoptosis in H. pylori CagA-Treated Gastric Cancer Cells by Regulating SP1 and HSF1 Expressions. Toxicology in Vitro, 31, 158-166. https://doi.org/10.1016/j.tiv.2015.09.025

[19] Li, Y., Lu, J., Bai, F., Xiao, Y., Guo, Y. and Dong, Z. (2018) Ginsenoside Rg3 Suppresses Proliferation and Induces Apoptosis in Human Osteosarcoma. BioMed Research International, 2018, Article ID: 4306579. https://doi.org/10.1155/2018/4306579

[20] Wang, J.H., Nao, J.F., Zhang, M. and He, P. (2014) 20(s)-ginsenoside Rg3 Promotes Apoptosis in Human Ovarian Cancer HO-8910 Cells through PI3K/Akt and XIAP Pathways. Tumor Biology, 35, 11985-11994.

https://doi.org/10.1007/s13277-014-2497-5

[21] Duan, Z., Wei, B., Deng, J., Mi, Y., Dong, Y., Zhu, C., et al. (2018) The Anti-Tumor Effect of Ginsenoside Rh4 in MCF-7 Breast Cancer Cells in Vitro and in Vivo. Biochemical \& Biophysical Research Communications, 499, 482-487.

https://doi.org/10.1016/j.bbrc.2018.03.174

[22] Wu, Q., Deng, J., Fan, D., Duan, Z., Zhu, C., Fu, R., et al. (2017) Ginsenoside Rh4 Induces Apoptosis and Autophagic Cell Death through Activation of the ROS/JNK/p53 Pathway in Colorectal Cancer Cells. Biochemical Pharmacology, 148, 64-74. https://doi.org/10.1016/j.bcp.2017.12.004

[23] Li, B., Zhao, J., Wang, C.Z., Searle, J., He, T.C., Yuan, C.S., et al. (2011) Ginsenoside Rh2 Induces Apoptosis and Paraptosis-Like Cell Death in Colorectal Cancer Cells through Activation of p53. Cancer Letters, 301, 185-192. https://doi.org/10.1016/j.canlet.2010.11.015

[24] Qian, J., Jing, L., Jia, J.-G., Xin, J. and Qian, L.-Y. (2016) Ginsenoside-Rh2 Inhibits Proliferation and Induces Apoptosis of Human Gastric Cancer SGC-7901 Side Population Cells. Asian Pacific Journal of Cancer Prevention, 17, 1817-1821. https://doi.org/10.7314/APICP.2016.17.4.1817

[25] Wu, T.L., Tong, Y.C., Chen, I.H., Niu, H.S. and Cheng, J.T. (2018) Induction of Apoptosis in Prostate Cancer by Ginsenoside Rh2. Oncotarget, 9, 11109-11118. https://doi.org/10.18632/oncotarget.24326

[26] Mao, Q., Zhang, P.H., Wang, Q. and Li, S.L. (2014) Ginsenoside F(2) Induces Apoptosis in Humor Gastric Carcinoma Cells through Reactive Oxygen Species-Mitochondria Pathway and Modulation of ASK-1/JNK Signaling Cascade in Vitro and in Vivo. Phytomedicine International Journal of Phytotherapy \& Phytopharmacology, 21, 515-522. https://doi.org/10.1016/j.phymed.2013.10.013

[27] Zhang, Y., Liu, Q.-Z., Xing, S.-P., et al. (2016) Inhibiting Effect of Endostar Combined with Ginsenoside Rg3 on Breast Cancer Tumor Growth in Tumor-Bearing Mice. Asia Pacific Journal of Tropical Medicine: English Version, 9, 180-183. https://doi.org/10.1016/j.apjtm.2016.01.010

[28] Zheng, K., Li, Y., Wang, S., Wang, X., Liao, C., Hu, X., et al. (2016) Inhibition of Autophagosome-Lysosome Fusion by Ginsenoside Ro via the ESR2-NCF1-ROS Pathway Sensitizes Esophageal Cancer Cells to 5-Fluorouracil-Induced Cell Death via the CHEK1-Mediated DNA Damage Checkpoint. Autophagy, 12, 1593-1613. https://doi.org/10.1080/15548627.2016.1192751

[29] Lv, D.L., Chen, L., Ding, W., Zhang, W., Wang, H.L., Wang, S., et al. (2018) Ginsenoside G-Rh2 Synergizes with SMI-4a in Anti-Melanoma Activity through Autophagic Cell Death. Chinese Medicine, 13, 11. https://doi.org/10.1186/s13020-018-0168-y

[30] Liu, Z.H., Chen, D.L., Rong, J., Yi, C., Wei, X., Wang, F., et al. (2016) Ginsenoside 
$\mathrm{Rh}_{2}$-Induced Inhibition of Histone Deacetylase 6 Promotes K562 Cells Autophagy and Apoptosis in Vivo. China Journal of Chinese Materia Medica, 41, 700-704.

[31] Sarkar, R., et al. (2014) Curcumin Augments the Efficacy of Antitumor Drugs Used in Leukemia by Modulation of Heat Shock Proteins via HDAC6. Journal of Environmental Pathology Toxicology \& Oncology, 33, 247-263. https://doi.org/10.1615/JEnvironPatholToxicolOncol.2014010913

[32] Chung, Y., Jeong, S., Choi, H.S., Ro, S. and Lee, J.S. (2018) Upregulation of Autophagy by Ginsenoside Rg2 in MCF-7 Cells. Animal Cells \& Systems, 22, 382-389. https://doi.org/10.1080/19768354.2018.1545696

[33] Yannan, L. and Daidi, F. (2018) Ginsenoside Rg5 Induces Apoptosis and Autophagy via Inhibition of PI3K/Akt Pathway against Breast Cancer in Mouse Model. Food \& Function, 9, 5513-5527. https://doi.org/10.1039/C8FO01122B

[34] Li, C., Dong, Y., Wang, L., Xu, G., Yang, Q., Tang, X., et al. (2019) Ginsenoside Metabolite Compound K Induces Apoptosis and Autophagy in Non-Small Cell Lung Cancer Cells via AMPK-mTOR and JNK Pathways. Biochemistry \& Cell Biology, 97, 406-414. https://doi.org/10.1139/bcb-2018-0226

[35] Ni, C., Li, Z. and Yang, H. (2014) Research Progress of Tumor Microenvironment and Tumor Cell Metastasis. Southwest Digestive Disease Academic Association Discussion and Guizhou Province Digestive Diseases and Digestive Endoscopy Academic Annual Meeting, Guizhou, 144-152.

[36] Furusato, B., Mohamed, A., Uhlén, M. and Rhim, J.S. (2010) CXCR4 and Cancer. Pathology International, 60, 497-505. https://doi.org/10.1111/j.1440-1827.2010.02548.x

[37] Chen, X.P., Qian, L.L., Jiang, H. and Chen, J.H. (2011) Ginsenoside Rg3 Inhibits CXCR4 Expression and Related Migrations in a Breast Cancer Cell Line. International Journal of Clinical Oncology, 16, 519-523. https://doi.org/10.1007/s10147-011-0222-6

[38] Pan, Z., Dafeng, Y.E., Xie, X. and Chen, H. (2002) Antiangiogenesis of Ginsenoside Rg3 in Severe Combined Immunodeficient Mice with Human Ovarian Carcinoma. Chinese Journal of Obstetrics \& Gynecology, 37, 227-230.

[39] Xu, T.-M., Cui, M.H., Xin, Y., Gu, L.-P., et al. (2008) Inhibitory Effect of Ginsenoside Rg3 on Ovarian Cancer Metastasis. Chinese Journal of Medicine (English), 121, 1394-1397. https://doi.org/10.1097/00029330-200808010-00012

[40] Lee, J.G., Mckinney, K.Q., Pavlopoulos, A.J., Park, J.H. and Hwang, S. (2015) Identification of Anti-Metastatic Drug and Natural Compound Targets in Isogenic Colorectal Cancer Cells. Journal of Proteomics, 113, 326-336. https://doi.org/10.1016/j.jprot.2014.10.009

[41] Qin, Y., Zhang, Q., Lee, S., Zhong, W.L. and Zhou, H.G. (2015) Doxycycline Reverses Epithelial-to-Mesenchymal Transition and Suppresses the Proliferation and Metastasis of Lung Cancer Cells. Oncotarget, 6, 40667-40679.

https://doi.org/10.18632/oncotarget.5842

[42] Chang, C.J., Chao, C.H., Xia, W., Yang, J.Y. and Hung, M.C. (2011) p53 Regulates Epithelial-Mesenchymal Transition (EMT) and Stem Cell Properties through Modulating miRNAs. Nature Cell Biology, 13, 317-323. https://doi.org/10.1038/ncb2173

[43] Thiery, J., Acloque, H., Huang, R.Y. and Nieto, M.A. (2009) Epithelial-Mesenchymal Transitions in Development and Disease. Cell, 139, 871-890. https://doi.org/10.1016/j.cell.2009.11.007

[44] Lim, H.K., Bae, W., Lee, H.S. and Jung, J. (2014) Anticancer Activity of Marine 
Sponge Hyrtios sp. Extract in Human Colorectal Carcinoma RKO Cells with Different p53 Status. Journal of Biomedicine and Biotechnology, 2014, Article ID: 413575. https://doi.org/10.1155/2014/413575

[45] Tian, L., Shen, D., Li, X., Shan, X., Wang, X., Yan, Q., et al. (2016) Ginsenoside Rg3 Inhibits Epithelial-Mesenchymal Transition (EMT) and Invasion of Lung Cancer by Down-Regulating FUT4. Oncotarget, 7, 1619-1632. https://doi.org/10.18632/oncotarget.6451

[46] Kim, Y.J., et al. (2014) Stereospecific Effects of Ginsenoside 20-Rg3 Inhibits TGF- $\beta$ 1-Induced Epithelial-Mesenchymal Transition and Suppresses Lung Cancer Migration, Invasion and Anoikis Resistance. Toxicology, 322, 23-33. https://doi.org/10.1016/j.tox.2014.04.002

[47] Liu, T., Zhao, L., Zhang, Y., Chen, W., Liu, D., Hou, H., et al. (2014) Ginsenoside 20(S)-Rg3 Targets HIF-1 $\alpha$ to Block Hypoxia-Induced Epithelial-Mesenchymal Transition in Ovarian Cancer Cells. PLOS ONE, 9, e103887. https://doi.org/10.1371/journal.pone.0103887

[48] Lee, J.M., Dedhar, S., et al. (2006) The Epithelial-Mesenchymal Transition: New Insights in Signaling, Development, and Disease. Journal of Cell Biology, 172, 973-981. https://doi.org/10.1083/jcb.200601018

[49] Zavadil, J., Cermak, L., Sotonieves, N. and Böttinger, E.P. (2004) Integration of TGF-beta/Smad and Jagged1/Notch Signalling in Epithelial-to-Mesenchymal Transition. Embo Journal, 23, 1155-1165. https://doi.org/10.1038/sj.emboj.7600069

[50] Attele, A.S., Wu, J.A. and Yuan, C.S. (1999) Ginseng Pharmacology: Multiple Constituents and Multiple Actions. Biochemical Pharmacology, 58, 1685-1693. https://doi.org/10.1016/S0006-2952(99)00212-9

[51] Konoshima, T., Takasaki, M. and Tokuda, H. (1997) Antitumor-Promoting Activities of Ginsenoside Rg1 and Panax Notoginseng. Springer, Berlin. https://doi.org/10.1007/978-4-431-67017-9 47

[52] Tie-Hua Z. (1994) Enhancing Effect of Ginsenoside Rg1 on LAK Cells Antitumor Activity in Vitro. Chinese Journal of Clinical Oncology, 21, 48-49.

[53] Li, Q., Shi, S.L., Liu, Q.R., Tang, J., Song, J. and Liang, Y. (2008) Anticancer Effects of Ginsenoside Rg1, Cinnamic Acid, and Tanshinone IIA in Osteosarcoma MG-63 Cells: Nuclear Matrix Downregulation and Cytoplasmic Trafficking of Nucleophosmin. International Journal of Biochemistry \& Cell Biology, 40, 1918-1929. https://doi.org/10.1016/j.biocel.2008.01.031

[54] Yu, M., Yu, X., Guo, D., Yu, B., Li, L., Liao, Q., et al. (2015) Ginsenoside Rg1 Attenuates Invasion and Migration by Inhibiting Transforming Growth Factor- $\beta 1$-Induced Epithelial to Mesenchymal Transition in HepG2 Cells. Molecular Medicine Reports, 11, 3167-3173.

https://doi.org/10.3892/mmr.2014.3098

[55] Liu, D., Liu, T., Zhao, L. and Xu, L. (2017) Ginsenoside Rg1 Regulating NF-(kappa)B to Block Hypoxia for Inducing EMT in Ovarian Cancer Cell SKOV3. Chinese Journal of Woman \& Child Health Research, 28, 273-275+278.

[56] Wang, P., Du, X., Xiong, M., Cui, J., Yang, Q., Wang, W., et al. (2016) Ginsenoside Rd Attenuates Breast Cancer Metastasis Implicating Derepressing Microrna-18a-Regulated Smad2 Expression. Scientific Reports, 6, Article No. 33709. https://doi.org/10.1038/srep33709

[57] Yoon, J.H., Choi, Y.J., Cha, S.W. and Lee, S.G. (2012) Anti-Metastatic Effects of Ginsenoside Rd via Inactivation of MAPK Signaling and Induction of Focal Adhesion Formation. Phytomedicine International Journal of Phytotherapy \& Phyto- 
pharmacology, 19, 284-292. https://doi.org/10.1016/j.phymed.2011.08.069

[58] Guan, N., Huo, X., Zhang, Z., Zhang, S., Luo, J. and Guo, W. (2015) Ginsenoside Rh2 Inhibits Metastasis of Glioblastoma Multiforme through Akt-Regulated MMP13. Tumor Biology, 36, 1-7. https://doi.org/10.1007/s13277-015-3387-1

[59] Jung, J.S., Ahn, J.H., Le, T.K., Kim, D.H., Kim, H.S. (2013) Protopanaxatriol Ginsenoside Rh1 Inhibits the Expression of Matrix Metalloproteinases and the in Vitro Invasion/Migration of Human Astroglioma Cells. Neurochemistry International, 63, 80-86. https://doi.org/10.1016/j.neuint.2013.05.002

[60] Han, S., Jeong, A.J., Yang, H., Bin Kang, K., Lee, H., Yi, E.H., et al. (2016) Ginsenoside 20(S)-Rh2 Exerts Anti-Cancer Activity through Targeting IL-6-Induced JAK2/STAT3 Pathway in Human Colorectal Cancer Cells. Journal of Ethnopharmacology, 194, 83-90. https://doi.org/10.1016/j.jep.2016.08.039

[61] Phi, L.T.H., Wijaya, Y.T., Sari, I., Yang, Y.G., Lee, Y.K. and Kwon, H.Y. (2018) The Anti-Metastatic Effect of Ginsenoside Rb2 in Colorectal Cancer in an EGFR/SOX2 Dependent Manner. Cancer Medicine, 7, 5621-5631.

https://doi.org/10.1002/cam4.1800

[62] Liu, D., Liu, T., Teng, Y., Chen, W., Zhao, L. and Li, X. (2017) Ginsenoside Rb1 Inhibits Hypoxia-Induced Epithelial-Mesenchymal Transition in Ovarian Cancer Cells by Regulating microRNA-25. Experimental \& Therapeutic Medicine, 14, 2895-2902. https://doi.org/10.3892/etm.2017.4889

[63] Park, T.Y., Park, M.H., Shin, W.C., Rhee, M.H., Seo, D.W., Cho, J.Y., et al. (2008) Anti-Metastatic Potential of Ginsenoside Rp1, a Novel Ginsenoside Derivative. Biological \& Pharmaceutical Bulletin, 31, 1802. https://doi.org/10.1248/bpb.31.1802

[64] Akao, T., Kanaoka, M. and Kobashi, K. (1998) Appearance of Compound K, a Major Metabolite of Ginsenoside Rb1 by Intestinal Bacteria, in Rat Plasma after Oral Administration-Measurement of Compound $\mathrm{K}$ by Enzyme Immunoassay. Biological \& Pharmaceutical Bulletin, 21, 245-249. https://doi.org/10.1248/bpb.21.245

[65] Zhang, K. and Li, Y. (2015) Effects of Ginsenoside Compound K Combined with Cisplatin on the Proliferation, Apoptosis and Epithelial Mesenchymal Transition in MCF-7 Cells of Human Breast Cancer. Pharmaceutical Biology, 54, 561-568. https://doi.org/10.3109/13880209.2015.1101142

[66] Ha, G.H., Park, J.S. and Breuer, E.K.Y. (2013) TACC3 Promotes Epithelial-Mesenchymal Transition (EMT) through the Activation of PI3K/Akt and ERK Signaling Pathways. Cancer Letters, 332, 63-73.

https://doi.org/10.1016/j.canlet.2013.01.013

[67] Chia, S., Gandhi, S., Joy, A.A., Edwards, S., Gorr, M., Hopkins, S., et al. (2015) Novel Agents and Associated Toxicities of Inhibitors of the pi3k/Akt/mtor Pathway for the Treatment of Breast Cancer. Current Oncology, 22, 33-48.

https://doi.org/10.3747/co.22.2393

[68] Yang, J., Zeng, Z., Peng, Y., Chen, J., Pan, L. and Pan, D. (2014) IL-7 Splicing Variant IL-7 $\delta 5$ Induces EMT and Metastasis of Human Breast Cancer Cell Lines MCF-7 and BT-20 through Activation of PI3K/Akt Pathway. Histochemistry \& Cell Biology, 142, 401-410. https://doi.org/10.1007/s00418-014-1222-1

[69] Peng, W.T., Sun, W.Y., Sun, J.C., Du, J.J. and Wei, W. (2018) Effects of Ginsenoside CK on Migration and Invasion of Human Hepatoma Cell Line HepG2. Chinese Pharmacology Bulletin, 34, 27-32.

[70] Han, M.S., Han, I.H., Lee, D., An, J.M., Kim, S.N., Shin, M.S., et al. (2016) Beneficial Effects of Fermented Black Ginseng and Its Ginsenoside 20(S)-Rg3 against Cispla- 
tin-Induced Nephrotoxicity in LLC-PK1 Cells. Journal of Ginseng Research, 40, 135-140. https://doi.org/10.1016/j.jgr.2015.06.006

[71] Park, J.Y., Choi, P., Kim, T., Ko, H., Kim, H.K., Kang, K.S., et al. (2015) Protective Effects of Processed Ginseng and Its Active Ginsenosides on Cisplatin-Induced Nephrotoxicity: In Vitro and in Vivo Studies. Journal of Agricultural and Food Chemistry, 63, 5964-5969. https://doi.org/10.1021/acs.jafc.5b00782

[72] Wang, J., Tian, L., Khan, M.N., Zhang, L., Chen, Q., Zhao, Y., et al. (2018) Ginsenoside Rg3 Sensitizes Hypoxic Lung Cancer Cells to Cisplatin via Blocking of NF-kappaB Mediated Epithelial-Mesenchymal Transition and Stemness. Cancer Letters, 415, 73-85. https://doi.org/10.1016/j.canlet.2017.11.037

[73] Lee, C.K., Park, K.K., Chung, A.S. and Chung, W.Y. (2012) Ginsenoside Rg3 Enhances the Chemosensitivity of Tumors to Cisplatin by Reducing the Basal Level of Nuclear Factor Erythroid 2-Related Factor 2-Mediated Heme Oxygenase-1/NAD(P)H Quinone Oxidoreductase-1 and Prevents Normal Tissue Damage by Scavenging Cisplatin-Induced Intracellular Reactive Oxygen Species. Food and Chemical Toxicology, 50, 2565-2574. https://doi.org/10.1016/j.fct.2012.01.005

[74] Tang, Y.C., Zhang, Y., Zhou, J., Zhi, Q., Wu, M.Y., Gong, F.R., et al. (2017) Ginsenoside Rg3 Targets Cancer Stem Cells and Tumor Angiogenesis to Inhibit Colorectal Cancer Progression in Vivo. International Journal of Oncology, 52, 127-138. https://doi.org/10.3892/ijo.2017.4183

[75] Jiang, J., Yuan, Z., Sun, Y., Bu, Y., Li, W. and Fei, Z. (2017) Ginsenoside Rg3 Enhances the Anti-Proliferative Activity of Erlotinib in Pancreatic Cancer Cell Lines by Downregulation of EGFR/PI3K/Akt Signaling Pathway. Biomedicine \& Pharmacotherapy, 96, 619-625. https://doi.org/10.1016/j.biopha.2017.10.043

[76] Deng, S., Wong, C.K.C., Lai, H.C. and Wong, A.S.T. (2017) Ginsenoside-Rb1 Targets Chemotherapy-Resistant Ovarian Cancer Stem Cells via Simultaneous Inhibition of Wnt/beta-Catenin Signaling and Epithelial-to-Mesenchymal Transition. Oncotarget, 8, 25897-25914. https://doi.org/10.18632/oncotarget.13071

[77] Nakata, H., Kikuchi, Y., Tode, T., Hirata, J., Kita, T., Ishii, K., et al. (1998) Inhibitory Effects of Ginsenoside Rh2 on Tumor Growth in Nude Mice Bearing Human Ovarian Cancer Cells. Japanese Journal of Cancer Research, 89, 733-740. https://doi.org/10.1111/j.1349-7006.1998.tb03278.x

[78] Yun, U.J., Lee, J.H., Koo, K.H., Ye, S.K., Kim, S.Y., Lee, C.H., et al. (2013) Lipid Raft Modulation by Rp1 Reverses Multidrug Resistance via Inactivating MDR-1 and Src Inhibition. Biochemical Pharmacology, 85, 1441-1453. https://doi.org/10.1016/j.bcp.2013.02.025

[79] Chian, S., Zhao, Y., Xu, M., Yu, X. and Yin, L. (2019) Ginsenoside Rd Reverses Cisplatin Resistance in Non-Small-Cell Lung Cancer A549 Cells by Downregulating the Nuclear Factor Erythroid 2-Related Factor 2 Pathway. Anti-Cancer Drugs, 30, 838-845. https://doi.org/10.1097/CAD.0000000000000781 